\title{
Generar nueva riqueza con responsabilidad social: la meta del gerente financiero*
}

\author{
[Artículos]
}

\author{
Alberto Parra Barrios**
}

Recibido: 26 de noviembre de 2020

Aprobado: 07 de abril de 2021

Citar como:

Parra, A., (2021). Generar nueva riqueza con responsabilidad social: La meta del gerente financiero. Revista Activos, 19(1).

https://doi.org/10.15332/25005278.6686

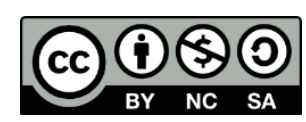

\section{Resumen}

El gerente financiero tiene una responsabilidad frente el inversionista. $\mathrm{Su}$ compromiso es maximizar la rentabilidad de la inversión, de modo que cree nueva riqueza para el propietario, tomando decisiones que se orienten al logro de este objetivo con una orientación o responsabilidad social.

\footnotetext{
* El presente artículo nace de una inquietud originada por los diferentes conceptos del objetivo del gerente financiero, presentada por los economistas autores de textos en finanzas, quienes consideran que la maximización del valor y la riqueza debe motivarlos. Pero este debe ser consistente con la RSE, que involucra a los stakeholders que se relacionan con la empresa. ** Administrador de empresas por la Universidad Javeriana, especialista en Finanzas por la Universidad de los Andes, magíster en Finanzas y Mercados Financieros por la Universidad San Pablo CEU en Administración de Negocios con énfasis en Finanzas por la Universidad Sergio Arboleda, en Economía por la Universidad Javeriana y en Administración Financiera por la Universidad Sergio Arboleda. Docente de finanzas en el posgrado de la Universidad Sergio Arboleda y docente investigador en la Fundación Universitaria Cervantes San Agustín. Correo electrónico: albertoparra9@yahoo.com; ORCID: http://orcid.org/0000-0003-1173-3073
}

\section{Revista Activos}

ISSN: 0124-5805 | e-ISSN: 2500-5278 | DOI: https://doi.org/10.15332/25005278

Vol. 19 N.o 1 | enero-junio de 2021 
Este trabajo pretende que el gerente financiero, en el momento de decidir sobre la orientación de sus recursos monetarios y económicos, reflexione sobre cuál es el impacto que genera en los diferentes actores que participan en el proceso productivo y en la consecución de beneficios económicos para los dueños de la empresa. En este sentido, se analiza la relación jurídica entre la empresa y la sociedad, así como la creación de valor para los stakeholders, que debe ser recíproca. Al final, se concluye que la suma de estos valores generados crea nueva riqueza o valor para el accionista.

Palabras clave: responsabilidad social, valor, empresa y sociedad, medio ambiente, Iglesia católica.

Clasificación JEL: M14, M29.

\section{Generating new wealth with social responsibility: the goal of the financial manager}

\section{Abstract}

The Financial Manager has a responsibility towards the investor. Its commitment is to maximize the profitability of the investment, so that it creates new wealth for the owner, making decisions oriented to the achievement of this objective with a social orientation or responsibility. This paper intends that the financial manager, at the moment of deciding on where to direct his monetary and economic resources, reflects on the impact he generates on the different actors who participate in the productive process and in the achievement of economic benefits for the company owners. In this sense, the legal relationship between the company and society is analyzed, as well as the creation of value for stakeholders, relationship that must be reciprocal. In the end, it is 
concluded that the sum of these generated values creates new wealth or value for the shareholder.

Keywords: social responsibility, value, business and society, environment, catholic church.

JEL classification: M14, M29.

\section{Introducción}

El presente trabajo cuestiona el actual proceso para la toma de decisiones financieras al interior de todo tipo de empresas, cuyo fin es alcanzar la maximización de la rentabilidad del capital accionario o capital social, a través del mayor incremento de dinero en el patrimonio. En muchos casos, se desvía la proyección social de la empresa y la creación de valor para quienes están en su entorno y contribuyen a la creación de esa riqueza.

En primer lugar, se hace un análisis del rol que desempeña la empresa y el inversionista frente a la sociedad. En este se muestra la relación que existe entre estos tres elementos, lo que permite comprender la responsabilidad social del ente jurídico a través del cual hace presencia el empresario y sus directivos.

En segundo lugar, se analiza el objetivo financiero como la maximización del patrimonio o la creación de nueva riqueza, vinculada a la responsabilidad de la empresa en la sociedad, mostrando el amplio entorno que impacta con sus decisiones. En este sentido, se comentan las responsabilidades de la empresa hacia la parte externa y se vincula el impacto de sus decisiones cuando define qué hacer o cómo mejorar sus beneficios económicos con relación a la creación de valor para los diferentes stakeholders, con los cuales interactúa a diario para satisfacer finalmente los intereses del inversionista.

Se concluye que el objetivo financiero que debe motivar al gerente de finanzas de la empresa debe ser buscar la creación de valor para el 
accionista como consecuencia de la creación de valor para cada uno de los actores con los cuales el ente jurídico tiene una relación contractual, reciproca y compromiso social.

\section{Problema conceptual}

El presente estudio parte de una pregunta a partir de la actual interpretación del objetivo que guía las acciones del gerente financiero en todo tipo de empresas, erradamente interpretada como la maximización de la rentabilidad o maximización del patrimonio del inversionista: ¿̇e trata solo de un objetivo económico?

El empresario y los directivos vinculados al área financiera de sus empresas han interpretado como objetivo financiero la búsqueda de mayores utilidades, es decir, un fin netamente económico. Ezra Solomon (1972), con una visión futurista muy clara sobre los intereses del inversionista, menciona: "La empresa y el inversionista no tienen otro propósito y no reconocen otro criterio decisorio que el de las utilidades y las persiguen tan simple e irresponsablemente como pueden". Profundizando este contenido, expresa más adelante que estas utilidades deben ser entregadas a los accionistas como dividendos, de modo que satisfaga una máxima tasa de interés. Lo interesante es que, al satisfacerlos con la más alta tasa de interés, van dando un poder económico al inversionista a tal punto que le ayudan a "engrandecer su ego" y a "exaltar o elevar" su orgullo ante la sociedad.

La mínima tasa de inversión o interés de oportunidad del inversionista se convierte en la tasa máxima que supere el promedio del rendimiento del mercado, y oriente las actividades y operaciones al logro de los mayores beneficios económicos que muestren el crecimiento de los valores monetarios, o mayor cantidad de billetes en el patrimonio de la empresa. De esta forma, al alcanzar las mayores utilidades, se satisfacen los 
intereses económicos de sus dueños y sus directivos. Esto es tan cierto que en el medio financiero empresarial, cuando se le pregunta a un inversionista o a un directivo cuál es el objetivo financiero que los mueve, sencillamente responden: "Ganar dinero... Hacer plata", frase que se ha convertido en la respuesta automática que marca el propósito fundamental del sector empresarial.

En la mayoría de los casos, como se ha mencionado, esta motivación lleva diariamente a directivos y empresarios a tomar decisiones equivocadas, aunque ellos no lo vean porque impactan positivamente las utilidades, pero negativamente la imagen personal y empresarial, dado el riesgo de reputación que ellas implican. En otros casos, se afecta negativamente a los directivos, al haber utilizado el capital de la empresa para beneficio personal, lo que los conduce a la pobreza de un momento a otro por no haber alcanzado la satisfacción de sus necesidades personales. Además, nace junto a ellas una equivocada interpretación de valores, pues lo que motiva la gestión financiera y económica son unos nuevos referentes externos, que se buscan a como dé lugar, porque ese poder económico que se desprende es lo que la sociedad, curiosamente, valora y respeta, aplaude y acepta.

\section{Revisión de la literatura}

Para comprender la interrelación de la empresa con la sociedad, conviene partir de un análisis de la naturaleza, los fundamentos jurídicos y los conceptos de economistas y estudiosos de la función económico-financiera empresarial.

Definir la 'responsabilidad social empresarial' (RSE) o 'responsabilidad social corporativa' (RSC) no es tan sencillo. Hoy en día coexisten diversas definiciones; es un concepto que involucra teorías y enfoques que inducen 
a las organizaciones a mantener unas buenas relaciones con la sociedad ${ }^{1}$. Las teorías son los principios que se establecen con el propósito de dar a conocer la responsabilidad empresarial y los enfoques son los puntos de vista adoptados por las empresas. Dada la diversidad de teorías, existen muchas definiciones sobre RSE, puesto que es un concepto muy amplio que puede decir mucho y nada en concreto al mismo tiempo, tal como lo afirman Flores et al. (2007). Para Votaw (1972) la "responsabilidad social significa algo, pero no siempre lo mismo a todo el mundo". Sin embargo, a pesar de la existencia de múltiples definiciones, en el fondo estas coinciden en la necesidad de promover e impulsar buenas prácticas en las empresas y sus negocios con responsabilidad en el impacto interno y externo para generar productividad en su actividad económica.

Por otro lado, para Tinoco-Cantillo et al. (2012) las teorías sobre RSE se centran en las interacciones entre la empresa y la sociedad. Se basan en cuatro aspectos observados en un sistema social: la adaptación al medio, el logro de los objetivos, la integración social y un patrón relacionado con la cultura y los valores; estos dan origen a las teorías instrumentales, las teorías de carácter político, las teorías integradoras y las teorías éticas.

Las teorías instrumentales estudian las actividades sociales que permiten alcanzar objetivos de creación de riqueza empresarial; comprende los enfoques de maximización del valor para el accionista, de mercadeo de causa social y estrategias de las empresas para lograr ventajas competitivas. Las teorías de carácter político enfatizan en el poder social que adquiere la empresa en la medida que se incrusta en la sociedad y no

\footnotetext{
1 Para Cajiga (2011) la responsabilidad social empresarial "es el compromiso consciente y congruente de cumplir integralmente con la finalidad de la empresa, tanto en lo interno como en lo externo, considerando las expectativas económicas, sociales y ambientales de todos sus participantes, demostrando respeto por la gente, los valores éticos, la comunidad y el medio ambiente, contribuyendo así a la construcción del bien común"; llama la atención esta definición que involucra aspectos internos y externos que tienen que ver con los grupos de interés que interactúan entre la empresa y la sociedad.
} 
requieren de creación de riqueza para ser empresa responsable; incluyen los enfoques del constitucionalismo corporativo, el contrato social y la ciudadanía corporativa.

Las teorías integradoras, mediante una serie de propuestas, buscan explicar el desarrollo de actividades de responsabilidad social empresarial por el deseo de captar, identificar y responder a las demandas sociales que vienen a ser la forma de comunicación entre la empresa y la sociedad. Los enfoques que incluyen este grupo de teorías integradoras son la gestión de asuntos sociales, la responsabilidad pública, la gestión de los grupos involucrados y el desempeño social corporativo. Las teorías éticas plantean los requisitos que mantienen la relación empresa-sociedad y se basan en los principios de los que debe y no debe hacerse para construir una mejor sociedad; comprenden los enfoques de grupos normativos involucrados, los derechos universales, el desarrollo sostenible y el bien común.

En el grupo de teorías integradoras se puede incluir el enfoque de la Iglesia católica, con una orientación netamente ética y de justicia social, el cual se puede observar con sus aportes desde los documentos escritos en el Vaticano, y las manifestaciones y participación en actividades de tipo caritativo en el siglo XIX y siglo XX (Sanborns y Portocarrero, 2003). Entre estas participaciones se pueden mencionar las encíclicas de pontífices orientadores de la Iglesia católica en años 1963 y 1991, y hechos destacados como los tratados por Tinoco-Cantillo (2012)2 como la participación de la Fundación Grupo Social en Colombia desde inicios del siglo XX.

Siguiendo a Doménec Melé (2004), podemos ver la historia empresarial y su vinculación con la sociedad. En los siglos XIV-XV y XVI aparecen los

\footnotetext{
${ }^{2}$ La Fundación Grupo Social fue creada por el padre jesuita José María Campoamor en 1911, inicialmente bajo el nombre de Círculo de Obreros de San Francisco Javier (Tinoco-Cantillo, 2012, p. 198).
} 
primeros emprendedores que desarrollaron la banca. Crearon sus empresas como entidades a las cuales los monarcas concedían derechos especiales para que realizaran negocios en sus dominios. En Inglaterra, hacia 1612, se formaron compañías con aportes de personas que dan origen a las hoy conocidas sociedades anónimas. A mediados del siglo XIX, los interesados en crear empresas recibían una carta real, con lo que se configuraba una autorización del poder público con fines de carácter público y condiciones especiales, que no pasó de ser una persona ficticia con derechos y obligaciones creada por la Ley. A finales del siglo XIX la "empresa comenzó a verse como una manifestación de libertad y expresión del derecho de propiedad y de iniciativa privada" (Melé, p. 156) por lo que dejó de lado la determinación del poder público.

En el siglo XX, se encontraron empresas en regímenes totalitarios, en dictaduras con reminiscencias que aún se mantienen en nuestros días. En los países comunistas las empresas se creaban como un derecho del Estado y, aunque hoy no se consideran como una concesión del poder público, sí se imponen obstáculos para su creación.

De esta forma, la relación empresa-sociedad se limita a una responsabilidad estrictamente legal. La visión de empresa-sociedad era muy pobre con relación a razones antropológicas y éticas. En este sentido, no hay que olvidar que la iniciativa emprendedora involucra la libre iniciativa, la asociación, el uso de la propiedad privada, el comercio, el beneficio económico razonable, el respeto a los derechos humanos y el uso de propósitos lícitos por el bien común y no atenten contra él. Estos son elementos muy importantes en la responsabilidad del empresario con el entorno en el que se desenvuelve.

A finales del siglo XIX se comenzó a hablar de la empresa como el resultado de una serie de acuerdos que se materializan en contratos. Para entonces, la empresa se concebía como un ente económico de carácter 
privado, y sus relaciones con la sociedad se limitan a la competencia en el mercado y la observancia de las leyes que rigen a estas organizaciones. La actual orientación económica neoliberal considera que la empresa es una relación de contratos en los cuales está incluido el individuo; así, no se ve el nexo entre compartir y colaborar solidariamente con las necesidades de quienes contribuyen en la transformación del producto y quien lo consume. Economistas reconocidos por su aporte financiero a la gestión empresarial aseguran que la función de la empresa es crear riqueza para el accionista (Ross et al., 2006); Brealey et al., 2007); Block y Hirt, 2001); Van Horne y Wachowicz, 2002). De hecho, los autores hacen hincapié en la creación de valor como el aspecto fundamental en la administración financiera de la empresa. Para Ross et al. (2006), este concepto debe ampliarse en el sentido de considerar no solo el volumen, sino cuándo esperan recibirlo y qué tan probable es que lo reciban. En pocas palabras, el impacto social originado en las decisiones al interior de la empresa está por fuera de su responsabilidad, al dejar ver en sus concepciones personales que esa responsabilidad se da solo al crear y generar riqueza económica. Se salen un poco de este contexto cuatro economistas. Brigham y Ehrhardt (2006) hablan de maximizar el precio de las acciones, mientras se beneficia a la sociedad en calidad de empresa y no a la sociedad en el sentido social de reconocimiento de valor a los integrantes que la conforman, como personas naturales y jurídicas. Bodie y Merton (1999) hablan de respetar las normas éticas y alcanzar las metas sociales, pero no especifican cuáles son los propósitos sociales.

En el sistema actual, la función del Estado es dictar normas y leyes para "evitar abusos" del empresario, derivados del deseo de hacer dinero. La empresa se ubica como una organización económica que pretende maximizar sus beneficios económicos, para que impacten positivamente el valor de sus acciones en el mercado de valores en beneficio de sus 
propietarios. Lo curioso es que no se trata con contundencia ese elemento ético que está implícito en las decisiones económicas y financieras vinculadas a los valores morales de los directivos y empresarios. Al respecto, el economista Friedman (1970) expresa: "La única responsabilidad de la empresa es la maximización de los beneficios para los accionistas respetando el marco legal y las costumbres éticas del país". Esta inquietante afirmación, desde la orientación económica, sugiere que la responsabilidad del empresario es exclusivamente económica y legal, a la vez que desplaza otro tipo de responsabilidades de impacto social como el desarrollo humano del empleado, la satisfacción de necesidades del consumidor al adquirir y consumir el bien o servicio. Dicha opinión la respalda el economista Michael Jensen (2002): "La maximización del valor para el accionista no es incompatible con satisfacer los intereses de los stakehorders o grupos interesados en la marcha de la empresa”. Aquí se está haciendo un planteamiento similar al de Milton Friedman, pues las exigencias de los grupos interesados en el desarrollo y crecimiento de la empresa donde priman los inversionistas son las que se aceptan, toda vez que conduzcan a la maximización del valor o creación de riqueza a largo plazo para la empresa, sin profundizar en la responsabilidad social. Con este enfoque, la relación empresa sociedad es netamente funcional, cada institución del Estado y cada empresa tienen una función específica con responsabilidades hacia la sociedad, pero limitadas a esa función.

A finales del siglo XX se observó una fuerte presión de la sociedad hacia las empresas para pedir acciones éticas, que hoy se ve nuevamente debilitada. La sociedad vuelve a aceptar acciones ilícitas en empresas del sector privado y sector público, que al final impactan negativamente a los grupos que interactúan con esas empresas y les resta valor por cuanto sus necesidades no se ven satisfechas totalmente. 
Esta posición de fortaleza y debilitamiento de la RSE amerita detenernos un poco para analizar hechos importantes en el desarrollo de la gestión en el mundo empresarial. A partir de los años 90, aparece una serie de organismos internacionales como la Comisión de las Comunidades Europeas, la Organización de las Naciones Unidas (ONU) por intermedio del Global Compact, el Programa de las Naciones Unidas para el Desarrollo (PNUD), la Organización Internacional del Trabajo (OIT) y la OCDE. Estas organizaciones se convirtieron en promotoras e impulsadoras de la RSE en el mundo, mediante diversas iniciativas como normas, guías, informes sociales, códigos de conducta, principios de buen gobierno corporativo, etiquetas sociales, instrumentos internacionales de derechos humanos, programas, e inclusive premios sobre responsabilidad social empresarial para las empresas más destacadas a nivel mundial (Instituto Colombiano de Normas Técnicas y Certificación [Icontec], 2006). Sin lugar a duda, la aparición de estos organismos conduce a que las empresas de variadas actividades económicas y sociales, grandes y pequeñas, incluyan en su Misión, Visión y Objetivos las actividades de responsabilidad social empresarial, por cuanto ellas le proyectan una imagen de beneficio y confianza en la sociedad. Pero conviene detenerse a analizar los resultados: especialmente en los últimos años, la sociedad es testigo de múltiples actividades de corrupción e incumplimiento de los valores y compromisos adquiridos por empresas reconocidas a nivel mundial que ponen en duda la transparencia de la RSE. Por citar algunas hechos, la relación y análisis que hacen Kaplan y Norton (2011) de empresas como Siemens, el banco Société Générale, la empresa de aviación Boeing (Dreamliner), la explosión de la plataforma petrolera Deepwater de British Petroleum, sugiere que bañaron de fraude y corrupción la imagen de sus compañías. A nivel local, en Colombia, un ejemplo son los escándalos que involucran a grupos económicos de primer 
nivel, dirigentes políticos y empresariales por sus actos dudosos como los relacionados con la firma Odebrecht. $\mathrm{Al}$ respecto es pertinente señalar la alta demanda de quejas en la sociedad que hoy reclama más transparencia empresarial, sanciones y control gubernamental.

En efecto, los criterios para alcanzar beneficios económicos y financieros utilizados por empresarios y dirigentes en materia de inversión han deteriorado el medio ambiente y económico, y han dejado en evidencia la poca transparencia en decisiones financieras en busca de utilidades; los escándalos financieros de empresas del Estado; el alto gasto del sector público en Colombia, en el que se desvían recursos a otras actividades diferentes al beneficio social; la corrupción a nivel estatal, divulgada por los medios de comunicación, y la precaria situación del trabajador colombiano, entre otros.

Por esta misma época, en los años noventa, aparecen otros enfoques que incluyen elementos importantes en la relación empresa-sociedad y se le da una connotación diferente a la responsabilidad social del empresario (RSE). Saldivar (1999), por ejemplo, describe las empresas como organismos sujetos a la influencia de factores externos e internos, cuyo funcionamiento está vinculado a la interacción de un sistema que incluye los elementos que lo componen y otros que lo integran, como el entorno en el cual se mueve. La empresa viene a ser un sistema tecnoeconómico y social conformado por elementos técnicos, económicos y humanos, que actúan coordinadamente para transformar recursos que obtienen de terceros y así finalmente ofrecer un producto o servicio útil a la sociedad. Aparece un elemento importante que es la persona, el ser humano como integrante fundamental de la sociedad y de la empresa.

Salekman (citado por Melé, 2004), explica que así las corporaciones empresariales se constituyan como entidades privadas con responsabilidades legales, tienen efectos sobre la sociedad al entregarles el 
producto final. Esto supone que los directivos a cargo deben responder positivamente a las expectativas del consumidor y provocar cambios en ellos. De esta manera, la empresa impacta a la sociedad y, a su vez, esta ejerce influencia sobre la empresa.

A este impacto de la sociedad se refieren Davis et al. (1980, p. 160) cuando afirman que la empresa es influenciada por los grupos del sistema y, a su vez, esta ejerce influencia sobre ellos; además, cuanto mayor poder tenga la empresa, tanto mayor será su responsabilidad frente a los elementos externos. El peligro está en que si no se utiliza adecuadamente este poder, la empresa puede ser sancionada o rechazada por la sociedad.

Otros autores también citados por Melé (2004, p. 160), como John Galbraith, consideran que la relación empresa-sociedad supone la existencia de una tecnoestructura que proporciona un sistema de valores e involucra los grupos sociales donde se encuentran otras empresas. Con una idea similar, Preston y Post (1975, en Melé, 2004, p. 160) describen la relación empresa-sociedad como una interpenetración de ambos sistemas a través de la cual cada una puede hacer cambiar la estructura de la otra. Por otro lado, se encuentran posturas provenientes de filósofos como Hobbes, Locke, Rousseau, también citados por Melé (2004, p. 162) quienes, desde el siglo XVII, ven la relación empresa-sociedad fundamentada en un contrato social que crea inquietudes con respecto al tratamiento de la empresa, al ser humano y a la autoridad para mantener el orden social en la sociedad. Para esto, Melé interpreta que las personas simplifican el problema a la concepción de la naturaleza humana y de las personas, con intereses y derechos, pero no trata en ninguna parte la sociabilidad y la solidaridad humana, elementos necesarios en la creación de valor. A continuación, el mismo autor, basándose en el concepto de Tom Donaldson (p. 163), afirma que en el contrato social debe existir una relación entre la empresa como una organización productiva y el individuo 
como miembro de la sociedad, con obligaciones y deberes. Desde este punto de vista, se muestra que hay una orientación acorde con el hecho de que los consumidores, los empleados y demás personas con intereses en la empresa son partes contratantes a quienes esta les debe satisfacer sus necesidades y ellos a su vez contribuir a incrementar los beneficios de ella. En este contexto de la RSE, es importante reiterar la concepción social de la Iglesia católica, que orienta su doctrina al bien común, a la dignidad de la persona y al crecimiento personal. Bien afirma que las instituciones sociales en donde se encuentra la empresa tienen como único fin contribuir al desarrollo integral del ser humano (Concilio Vaticano II, 1963).

La empresa, al estar inmersa en un conglomerado de instituciones que contribuyen a la satisfacción de necesidades del ser humano, sirve de nexo para que la persona individualmente se conecte con estas instituciones y facilite la agregación de valor, con el aporte que ellas hacen desde su campo de operación a los individuos que conforman la sociedad. En este orden de ideas, la encíclica de Juan Pablo II (1991) precisa la doctrina de la Iglesia católica:

La sociabilidad del hombre no se agota en el Estado sino que se realiza en diversos grupos intermedios, comenzando por la familia y siguiendo por los grupos económicos, sociales, políticos y culturales, los cuales provienen de la misma naturaleza humana, tienen su propia autonomía, sin salirse del ámbito del bien común. (Melé, p. 166)

Estas afirmaciones de la Iglesia católica contienen importantes fundamentos que hacen de la empresa un ente jurídico que sirve de medio conector entre el individuo y la sociedad a la cual ella pertenece. En primer lugar, la empresa encuentra su papel en la sociedad cuando analiza las necesidades del entorno en el cual se mueve y entrega un bien o servicio a 
los individuos, para satisfacer esas necesidades. En segundo término, el papel de la empresa en la sociedad está orientado a que beneficie a todos los miembros de la sociedad y no al bien individual. En tercer lugar, la empresa, al ser parte activa en la sociedad con orientación enfocada al bien común, contiene responsabilidades que recaen en los directivos que la representan. Entre estas, se puede enunciar que la toma de decisiones económicas, comerciales y administrativas implica una exigencia ética por cuanto la sociedad espera que sus actuaciones estén fundamentadas en la transparencia y en los valores morales, que se respeten los derechos de las personas, los contratos y acuerdos firmados y se actúe con justicia y equidad. En cuarto lugar, las decisiones que se tomen al interior de la empresa deben contribuir al bienestar, al desarrollo y a la satisfacción de las necesidades de los grupos involucrados en el desarrollo de la misma empresa.

Entonces, para la Iglesia católica es claro que la empresa es una comunidad dentro de la sociedad. Las empresas son parte de la sociedad, surgen en la sociedad, se nutren de la sociedad y proporcionan bienes y servicios a la comunidad con orientación social, para crear valor a la persona y a las demás organizaciones que están circunscritas en su entorno.

\section{La responsabilidad social empresarial frente a la sociedad: otros aportes}

Con el nacimiento de la administración de empresas como un arte para dirigir y gestionar organizaciones, según las teorías clásicas de la administración de Federick Taylor y Henry Fayol, a principios del siglo pasado, se buscaba, en últimas, la obtención y preservación del beneficio económico para sus propietarios a costas de la utilización y subordinación de los empleados. Posteriormente, hacia la década de los años cincuenta, 
se pensó en un mayor compromiso de la empresa para con la sociedad, y desde ese momento se presta más atención al desarrollo de los derechos humanos, de los empleados en la empresa, a la conservación del medio ambiente y a los efectos que puedan tener las acciones que se tomen dentro de la empresa hacia la sociedad.

El desarrollo de la administración empresarial muestra importantes planteamientos que contribuyen a la generación de valor para el talento humano, uno de los principales actores ante los cuales tiene responsabilidad social el empresario. La empresa no solo es una figura jurídica, sino que además es un sistema donde interactúan personas con otras empresas que también tienen derecho a crecer y desarrollarse utilizando recursos económicos y financieros.

De hecho, se han tomado acciones y hay una mayor difusión de la RSE pero falta comprender qué es realmente el concepto y cuál es la verdadera participación del empresario y la empresa en la sociedad. La responsabilidad social se ha confundido con entregar obsequios a los hijos de los empleados al final del año, con hacer una donación a una fundación y obtener una certificación para reducir el pago de impuestos o llevar a cabo actividades similares con la esperanza de obtener un beneficio económico personal.

La RSE deberá definir y establecer la relación empresa-sociedad y consecuentemente la acción de los sectores externos con ella. De esta manera, se configura prácticamente una conversación de doble vía, donde debe existir una reciprocidad motivada por haber recibido de la empresa un producto, servicio o el cumplimiento de una obligación a satisfacción.

Se desprende la necesidad de establecer la responsabilidad de la empresa con los grupos interesados en su crecimiento que trabajan con ella de manera conjunta para alcanzar propósitos económicos y sociales. 
Simultáneamente es necesario analizar las implicaciones que tiene el tomar decisiones adecuadas o no, desde el punto de vista del objetivo financiero de creación de valor o nueva riqueza para el accionista, pero desde la generación de valor para quienes están en su entorno.

Siguiendo a Paladino y Milberg (2004), en los años cincuenta se cuestionó el trabajo empresarial y se empezó a sugerir RSE con el planteamiento de Bowen, cuando afirma que "la obligación del directivo de empresa es perseguir políticas, tomar decisiones y seguir líneas de acción deseables para los objetivos y valores de la sociedad" (pp. 46). Hacia los años sesenta la RSE se enfocaba en el reconocimiento de la empresa, integrada al sistema social, y no puede actuar aisladamente pasando por alto el impacto que sus decisiones genere. Para Davis et al. (1980), la responsabilidad social del empresario es el deber de toda persona de tener en cuenta el impacto de sus actos en todo el sistema social, lo que implica que las decisiones y acciones de los empresarios van más allá de lo técnico y lo económico. Davis sostiene que "la responsabilidad social debe estar acorde con el poder social de las empresas" (Paladino y Milberg, 2004, p. 42). Por su parte, Frederick plantea que "los recursos económicos y humanos de la sociedad sean usados para fines sociales amplios no restringidos a los intereses exclusivos de la compañía” (Paladino y Milberg, 2004, p. 42).

Hacia los años ochenta se destacan dos conceptos: el de Peter Drucker, padre de la administración moderna, y el de Milton Friedman, economista representante de la economía neoliberal. Drucker (2001 [1984], p. 44) plantea que la empresa debe convertir su RSE en una oportunidad de negocio integrada a las necesidades de la sociedad, convertir los problemas sociales en una oportunidad de negocio, en capacidad de producción, en trabajos bien remunerados y en riqueza integrando a los trabajadores, empresarios y gerentes. Friedman (1970, en Paladino y Milberg, 2004, p. 
44) presenta la teoría de los stakeholders vinculando las empresas con la sociedad, en una relación de doble sentido, de tal manera que los intereses del accionista y de los stakeholders 3 deben estar incorporados a la empresa.

Hacia los años noventa, surge el concepto de 'desempeño social de la empresa', a través del cual se sugiere que la compañía debe responder a las demandas de la sociedad. Simultáneamente, nace el concepto de ciudadanía corporativa, que se define como la relación de la empresa en la sociedad, basada en que hay derechos y deberes para la empresa, similares a los de los ciudadanos. La empresa debe administrar las relaciones con los stakeholders y ocuparse también de la rentabilidad. La toma de consciencia de las implicaciones sociales de las prácticas operativas de la empresa y desarrollar políticas, procedimientos y procesos respetando la dignidad y valor de los stakeholders.

Por su parte, Donaldson (Paladino, 2004, pp. 46, 162-163) fundamenta la RSE en el contrato social. Las empresas no pueden existir sin el compromiso y la cooperación de la sociedad, si la sociedad rechaza el funcionamiento del sector empresario este debe transformarse. Por esta razón, existe un contrato social al ámbito empresarial: la empresa toma los empleados de la sociedad, vende sus productos y servicios a la sociedad, la sociedad los adquiere y ella es quien le otorga o retira un status. Todo el funcionamiento con leyes y regulaciones parece justificar la existencia de un contrato implícito entre la empresa y la sociedad; el problema está en

\footnotetext{
${ }^{3}$ Con relación a los grupos de interés, Paladino (2004, p. 45) considera que el sistema de stakeholders, ante quienes es responsable la empresa, se encuentra organizado en tres grupos: el grupo primario, constituido por los accionistas, los inversores, empleados, clientes y proveedores; un segundo grupo, conformado por quienes influyen o son influidos por la empresa, pero no participan de sus operaciones y movilizan la opinión pública a favor o en contra, y un tercer grupo, compuesto por el gobierno, comunidades que proporcionan la infraestructura y mercados cuyas leyes deben ser obedecidas y a quienes se les paga impuestos y obligaciones.
} 
que no es un contrato escrito, sino que las obligaciones que conlleva el contrato no están definidas.

Entre los años ochenta y dos mil se incluye el desarrollo sostenible, donde la empresa debe trabajar por el medio ambiente. Se pide a las empresas que no generen daños con sus actividades comerciales, lo que implica un desempeño ambiental con el que se asegura no tener un efecto perjudicial en el medio ambiente natural y biofísico a corto y largo plazo.

- Cambiar (satisfacer una necesidad) la vida de muchas personas, fijar la imagen de la empresa en la sociedad y obtener un beneficio económico a largo plazo.

- La empresa no puede verse como una entidad eminentemente económica, conformada por personas que circunscriben sus responsabilidades a lo económico, con lo que se mantiene una relación con la sociedad de carácter utilitarista.

- $\quad$ Friedman afirmaba que la obligación moral de los directivos empresariales era generar beneficios para los accionistas y no destinar recursos para otros fines, pues esto es robar a los propietarios.

Se puede decir que sí existe una responsabilidad de la empresa en la sociedad que va más allá de producir y generar utilidades como la acción tradicional. En efecto, hay una visión más amplia de la responsabilidad de la empresa de cara a la sociedad, a pesar de la existencia de detractores que se orientan exclusivamente por el lado capitalista.

\section{Creación de valor desde la óptica de los economistas}

Los economistas neoclásicos ubican al individuo en la búsqueda de la satisfacción desde el plano económico, como bien natural y objetivo del ser 
humano. En esta posición, la persona está más necesitada o condicionada materialmente.

La empresa, por su parte, es considerada según fines determinados, es reconocida como una unidad de producción y distribución sometida a unas reglas de la actividad humana que actúa con racionalidad y responsabilidad por lo que hace (Paladino, 2004). Es el lugar de trabajo del hombre, él la hace y en ella cumple una misión y una actividad de carácter individual y social.

Desde este enfoque, se concibe la tarea directiva como tarea humana y un trabajo ligado a la unidad productiva, un trabajo profesional de alguien que suministra un bien o servicio indispensable para la persona como ser humano. El bien o servicio no es la confección de un bien; es entregar una solución, es entregar algo a lo que el mercado le da un valor, y recompensar la contribución a la satisfacción. De aquí se desprende la riqueza para el empresario, que no es otra cosa que la valoración que hace la sociedad acerca del resultado de la actuación humana, realizada al interior de la empresa y que luego traslada al exterior.

El hombre pone sus cualidades intelectuales, técnicas y morales en el desempeño de su tarea. La empresa viene a ser una actividad del hombre de carácter interactivo dirigida a facilitar bienes materiales necesarios para crecer y sobrevivir. Pero la tarea directiva no consiste solamente en producir algo físico, sino entregar un bien al que la sociedad le da un valor económico como recompensa por las necesidades satisfechas.

Desde luego, el aspecto económico es condición necesaria pero no suficiente en la organización humana y es también valor y virtud en la medida que exista subordinación a fines superiores. Desde el interior de la empresa se crea un producto o servicio que se entrega al exterior para satisfacer una necesidad del ser humano. El proceso de transformación 
conduce a que el bien se orienta a un grupo de personas que buscan bienestar y que tiene que ver con su vida, a la satisfacción y el placer que siente una persona al obtener un producto o servicio. Dicha persona se encuentra fuera de la empresa, pero dentro de la sociedad a la cual pertenece la firma y los empleados. De ahí que se requiera de ciertas cualidades técnicas, éticas y afectivas para poner ese producto o servicio en manos de la sociedad para el crecimiento humano.

Conseguir el resultado económico a corto plazo no asegura la continuidad a largo plazo. Este resultado no se puede apartar de las circunstancias que le dan permanencia o tiende a desaparecer si se considera como lo primordial. El generar valor económico implica generar primero valor a quién trabaja desde adentro y a quien adquiere el producto, ambos como seres humanos.

Ese valor incluye las consideraciones éticas, pero lo ético no es un insumo del valor económico, como se trata de resaltar en textos y en empresas que promueven la obtención del dinero y la obtención de riqueza como propósito esencial en el ser humano. El directivo y el empresario deben pensar que lo económico es un insumo para el hombre y empresario ético. De esta manera, lo económico se encuentra supeditado a la misión de la empresa y a su estado de salud, para poder mantener a largo plazo un beneficio económico que provenga de satisfacer los propósitos de valor de quienes se encuentran en su entorno.

\section{La orientación del empresario y la gerencia financiera}

Pero, desde el interior de las empresas, ¿cómo se puede trabajar para lograr un proceso sostenible en el tiempo? La respuesta a esta pregunta da cabida a otra cuestión. Si los directivos de primer nivel, los funcionarios y los empresarios tienen que contribuir positivamente con sus acciones al desarrollo y crecimiento de la sociedad, ¿cuál es el papel que ellos deben 
desempeñar desde sus cargos para obtener los resultados económicos deseados, fundamentados en el cambio y la generación de valor para la empresa y la sociedad?

La gestión empresarial está condicionada por varios factores, dentro de los que se cuenta la tradición familiar, la motivación para crear negocios, la experiencia de los directivos, la actitud de las personas, la cultura empresarial, la cultura de las personas, el modelo organizacional implementado en el ente económico, los valores y virtudes de los directivos y de los empresarios. Independientemente de cuál sea la razón, los resultados, se proyectan reflejando una injusta distribución de la riqueza y desigualdad social que riñe con los principios sociales, ambos en muchos casos fomentados por misma empresa. En consecuencia, la empresa y sus directivos tienen que asumir una responsabilidad ante la sociedad, no limitando su gestión a los simples resultados económicos y la alta rentabilidad del patrimonio.

Los empresarios y los directivos, entonces, deben preguntarse qué más hay que hacer por la sociedad en la cual trabajan y para la cual deben trabajar, toda vez que de ella reciben los ingresos que generan utilidades para la empresa. El problema radica en que a pesar de que se habla de la responsabilidad social empresarial y se aplica en muchas empresas, no está totalmente aceptada o no incluye todos sus componentes:

Aún no está debidamente fundamentada como parte del deber ser de la empresa, no es tener un programa de voluntariado, no es participar en programas de ayuda a niños huérfanos o ayuda a escuelas con carencia de recursos; [la responsabilidad social] compromete a la empresa desde raíces más profundas que el mero asistencialismo o la respuesta a las demandas sociales del entorno. (Paladino, 2004, p. 39) 
La RSE debe estar fundamentada en una amplia visión integral de la responsabilidad directiva. No es mirar la fundamentación en los conceptos de ser solidarios con los pobres y darles de vez en cuando algo de lo que me queda, no es reducir el indicador de conflicto con el sector donde se encuentra mi empresa, no es aprovechar mi colaboración como una oportunidad de negocio para incrementar mis utilidades como empresario, no es tener una fundación social vinculada a "mi" grupo corporativo que depende de "mi" orientación y control, a la cual le destino parte de "mis utilidades" anualmente para evadir el pago de impuestos. Es orientar las decisiones, desde el interior de la empresa, para generar valor a los grupos de interés que trabajan en el entorno empresarial.

Aquí nacen las inquietudes de las personas y la sociedad en general, donde nace el problema de la RSE. Esta filosofía se está incluyendo en los planes estratégicos de empresas que presumen de tener políticas relacionadas con la responsabilidad social, pero que, por su falta de claridad, la sociedad lo ve más como una moda por las unidades económicas que como una función complementaria a sus responsabilidades. Entonces, el verdadero sentido social y la creación de valor para las partes no está dando los verdaderos resultados. Con el actual enfoque y la práctica empresarial, la RSE no se ve cómo la satisfacción de necesidades para quienes trabajan en las empresas y para quienes desde afuera contribuyen como empresas o instituciones al crecimiento y creación de nueva riqueza del empresario; solo un componente se ve beneficiado: el empresario.

\section{La toma de decisiones financieras y la responsabilidad social}

Se entiende que el objetivo operativo de la gerencia financiera es la creación de valor para la empresa y el accionista, concepto que también se interpreta como la maximización de la rentabilidad del patrimonio. Según 
Solomon (1972), este concepto define el objetivo operativo de la administración financiera como maximizar el valor actual neto, entendido como la creación de nueva riqueza desde el punto de vista económico y financiero. Pero esta maximización de la rentabilidad, o creación de nueva riqueza, debe contemplar la generación de valor para quieres contribuyen al crecimiento y el desarrollo de la empresa, los llamados stakeholders, identificados en tres grupos ya mencionados por Paladino (2004).

En consecuencia, la generación de utilidades a largo plazo o la generación de nueva riqueza para el accionista, debe estar basada, desde la óptica económica, en la creación de un patrimonio vitalicio fundamentado en la satisfacción de las necesidades de quienes actúan como stakeholders en el contexto económico y social en el que se desenvuelve la empresa. Esto ocurre cuando se trabaja con una relación empresa-sociedad, manteniendo el sentido social en la toma de decisiones de los empresarios y los directivos como un principio colaborativo para el mutuo desarrollo. Sobre esta base, no se puede excluir la responsabilidad ante la sociedad, por cuanto la motivación de la administración financiera moderna es poder llegar a satisfacer las necesidades de quien brinda las oportunidades para su crecimiento, sus beneficios económicos, la supervivencia y de quien recibe apoyo financiero.

Estos grupos de interés, que hemos denominado stakeholders, se clasifican en siete grandes sectores de influencia, para quienes se presenta una propuesta de valor desde la dirección y estrategia empresarial, que se pueden ver en la figura 1 y se describen a continuación:

\section{Primer componente: el consumidor}

Es el cliente, a él se le debe el ingreso que permite la generación de fondos operativos de la empresa; si no se le satisfacen sus necesidades con la entrega de un producto que llene sus expectativas, seguramente deja de 
consumirlo, cambia de empresa o busca un sustituto y se retira. La empresa deberá buscar la forma de mantener vinculado al consumidor para que le genere ese patrimonio vitalicio que en el presente contribuya a la maximización del capital. Para ello, el producto o servicio debe ser de calidad, satisfacer las necesidades del cliente, que sea el producto deseado, que el precio corresponda a esa satisfacción que recibe: que en definitiva le entregue valor. En estas condiciones, el consumidor, en la mayoría de las veces, poco se preocupa por el precio.

Figura 1. Representación de los grupos de interés para la empresa (stakeholders)

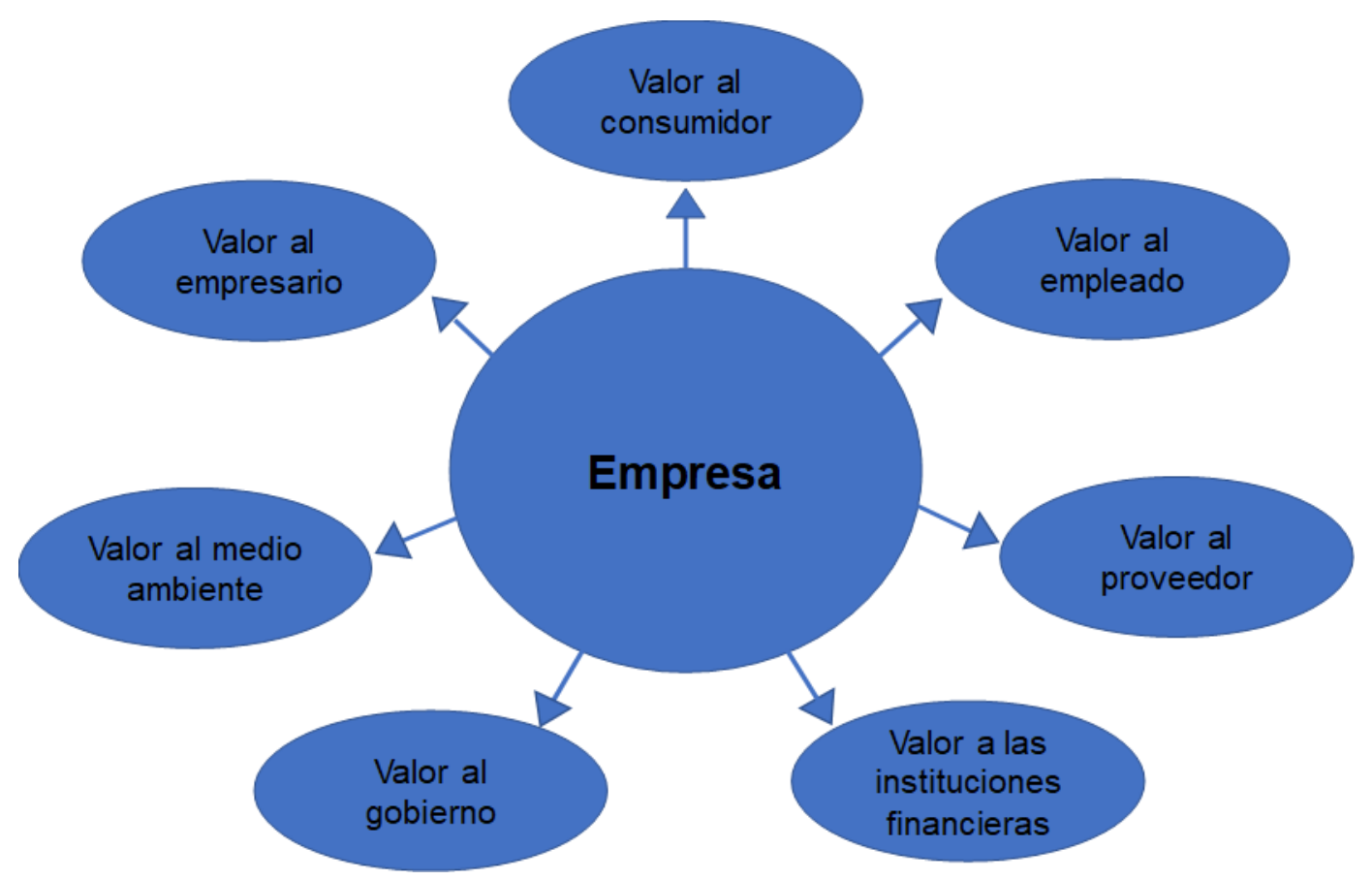

Fuente: elaboración propia.

La creación de valor para el consumidor busca fijar la imagen de la marca en su mente, de modo que lo haga fiel al producto y difícilmente la cambiará. Consiste en buscar que el consumo de sus productos tenga una tendencia creciente de ingresos que beneficie al accionista. 
En este caso, la estrategia de marca juega un papel importante en la creación de valor para el accionista, con lo que se pretende un flujo de ingresos incremental y sostenido a largo plazo que proviene del consumidor. La empresa debe pensar que el cliente se crea, se retiene y se hace crecer. Cuando esto ocurre, hay una alta satisfacción en el cliente por cuanto la empresa está enfocada en entregarle valor con su producto. Se busca construir una marca a largo plazo y una relación duradera con el cliente, su lealtad. La lealtad del consumidor se traduce en un liderazgo en ventas, un flujo de ingresos sostenido para la empresa y el retorno correspondiente para el accionista. En otras palabras, consiste en generar un patrimonio de marca que le permite a la empresa maximizar su patrimonio e incrementar el valor de la acción en el mercado; se relaciona con una propuesta de valor clara por la que el cliente esté dispuesto a elegir la empresa y pagar por un producto que lo llena. Por lo tanto, generar valor para el accionista, en este caso, es consecuencia de generar valor para el cliente (tabla 1 ).

Tabla 1. Valor de la marca y su relación con el cliente

\begin{tabular}{|c|c|}
\hline \multicolumn{1}{|c|}{\begin{tabular}{|c|}
\hline Empresa \\
\hline Apple
\end{tabular}} & Valor de capitalización de la marca \\
\hline Google & USD 234.241 M \\
\hline Amazon & USD 167.713 M \\
\hline Microsoft & USD 125.263 M \\
\hline Coca Cola & USD 108.847 M \\
\hline Samsung & USD 63.365 M \\
\hline Toyota & USD 61.098 M \\
\hline Medes Benz & USD 56.246 M \\
\hline Mc Donalds & USD 50.832 M \\
\hline Disney & USD 45.362 M \\
\hline BMW & USD 44.352 M \\
\hline IBM & USD 41.440 M \\
\hline
\end{tabular}


Fuente: elaboración propia, con base en Best Global Brands 2019 - Interbrand.

En el cuadro anterior se observa que estas empresas son altamente reconocidas por clientes globales y su valor de capitalización refleja la lealtad del cliente, al colocarlas como las 12 marcas más valiosas en 2019 entre 100 listadas en el ranking mundial. Desde el punto de vista económico, son empresas que tienen como objetivo maximizar el valor de los clientes para beneficio de los accionistas.

Cuando se habla de crear un cliente, debe entenderse que la empresa tiene que enfocarse en consentir y retener al cliente actual, el cual viene a ser excelente referencia para los no clientes, pero no concentrarse solo en el actual. Es importante concentrar su mirada también hacia los no clientes, preocupándose por conocer sus características con el fin de atraerlos, capturarlos y convertirlos en clientes, lo que podría posicionarla mejor en el mercado (Chan Kim y Mauborgne, 2005). En este sentido, la empresa tiene que ser consciente de que todos los clientes tienen problemas y mientras más ayude el producto o servicio a solucionarlo, mayor valor estará entregando al cliente. El enfoque es que la empresa se vea más a sí misma como proveedora de una solución, en lugar de proveedora de un producto, que entienda profundamente las necesidades de uso o consumo de su producto.

Pero no basta con implementar una estrategia de mercado que cree un patrimonio de marca y un patrimonio de clientes. La empresa tiene que entregar un producto de calidad, que satisfaga sus necesidades a un precio equivalente, sin engaños, sin trucos para vincularlo a su lista de consumidores; inclusive, la marca tiene que estar limpia de riesgos de reputación: "Si el mercado percibe que la institución comete errores en 
algún proceso clave de la operación, es lógico que los clientes consideraran eventualmente cambiar de institución" (De Lara Haro, 2004).

Esta creación de valor para el cliente está vinculada con el proceso de producción Lean. En el área de producción de la empresa, hay que optimizar el proceso de transformación para entregar el servicio o producto al cliente en el momento que lo necesita, justo a tiempo (JIT), inclusive antes de lo solicitado por él. Pensar en la reducción del proceso de producción es reducir la cadena de abastecimiento y ofrecer soluciones al cliente desde el interior de la empresa, donde él encuentre que la empresa está interesada en satisfacer sus necesidades confeccionando el producto o servicio que necesita en el menor tiempo posible, no entregarle lo que la empresa produce y quiere que él acepte. 
Figura 2. Representación gráfica del proceso de producción, la cadena de valor y su relación con el cliente

\section{Enfoque de producción basado en procesos}

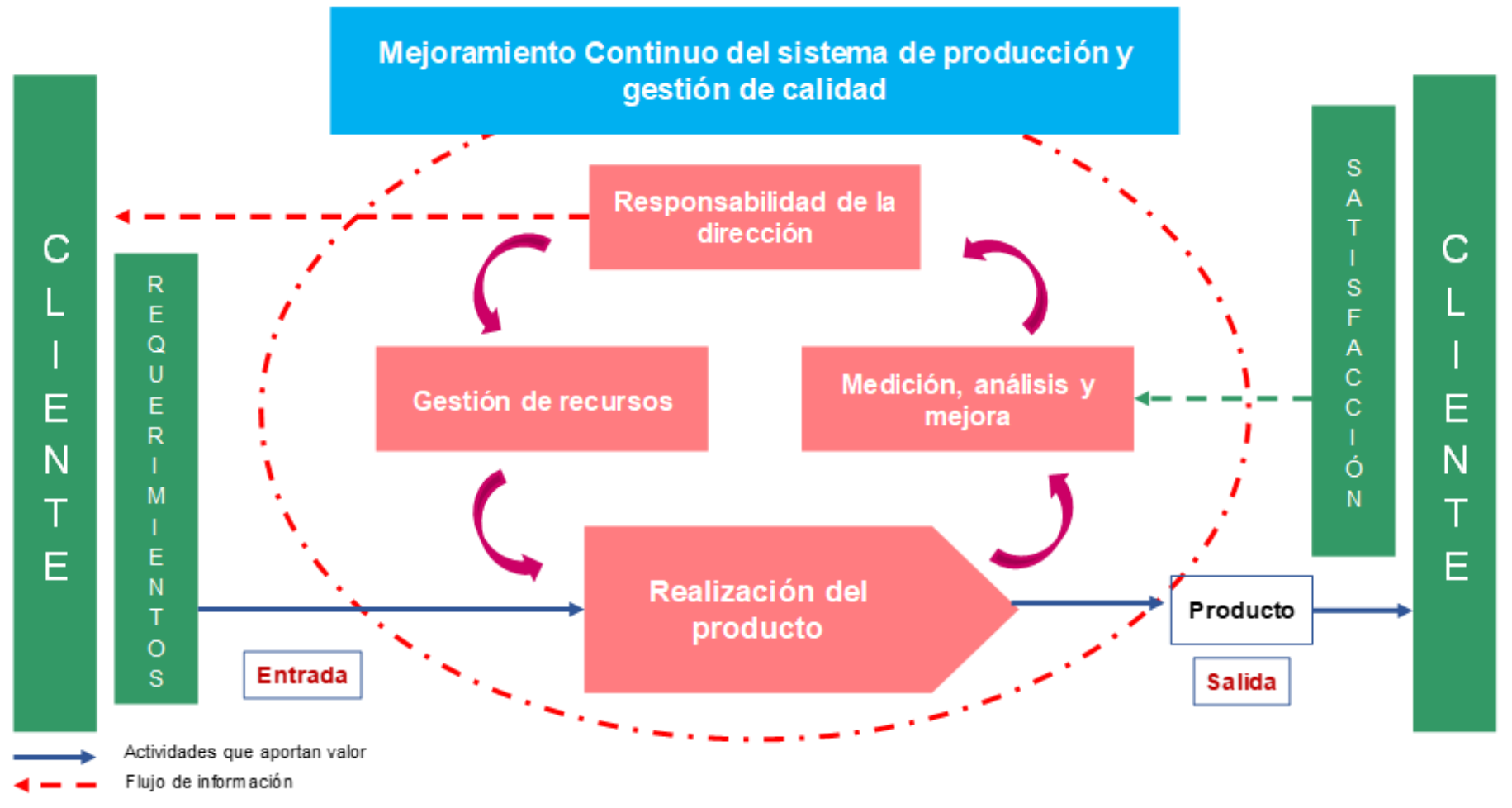

Fuente: elaboración propia. 
Si la cadena de abastecimiento es la función que integra los movimientos de todo lo relacionado con el abastecimiento de la cadena de valor del negocio, hay que integrar todo lo vinculado con la agregación longitudinal de valor desde los proveedores hasta los clientes para que no se frene la capacidad de respuesta. Es necesario lograr un flujo continuo de productos asociados con la demanda, un flujo de información continuo en línea, un flujo continuo de dinero y un flujo continuo colaborativo de conocimiento que incluye lograr alianzas antes y después del proceso. Esta orientación mejora los procesos y conduce a la efectividad a través de la integración. Este es el fundamento de la ISO 9000; la ISO 14000 es la fuerza al mejoramiento continuo para llegar con el producto de calidad al cliente. Saldivar (1999) analiza el mejoramiento de la eficiencia de las funciones empresariales mediante la optimización de procesos, equipos y métodos de trabajo más productivos, lo cual impacta positivamente las utilidades operativas al reducir los costos y mejorar la productividad.

Desde este punto de vista, el objetivo de la gestión de compras es el mejoramiento de la cadena de abastecimiento, para mejorar y aumentar la productividad de los integrantes, encontrar mejores opciones que satisfagan las necesidades de los clientes a menores costos y mejorar los servicios externos en el entorno que terminan formar parte de la red de abastecimiento.

Cuando la empresa administra el flujo de valor y planifica iniciativas "Lean" de mejoramiento a través de toda la cadena de valor para llevar un producto de calidad que satisfaga las necesidades del cliente en el momento que él lo requiere, se está creando una vinculación permanente en el largo plazo con el consumidor que va a representar un patrimonio vitalicio, en beneficio del accionista. 


\section{Segundo componente: el empleado}

La gerencia de talento humano debe agregar valor a los directivos y empleados para que le puedan dar los beneficios a los inversionistas y a los clientes. Para que el empleado contribuya a la generación de riqueza para el accionista y al crecimiento de la empresa, tendrá atención apropiada para su desarrollo personal, para desarrollar su estrategia de crecimiento al interior de la compañía, para elevar el estatus de su familia. La organización deberá crear un ambiente agradable de trabajo, entregar una buena retribución económica que satisfaga sus necesidades, acorde con el desempeño laboral, y buscar que el empleado eficiente y productivo elija quedarse en la empresa, de tal forma que el profesional que se encuentra fuera de ella quiera ingresar y el que está dentro de ella no quiera salir.

No se puede dejar pasar por alto la contribución que hacen desde mediados del siglo pasado pensadores que se refieren a los derechos humanos (que no se tratarán en detalle en este artículo) como Elton Mayo, Douglas McGregor, Peter Drucker y actuales orientadores de la estrategia empresarial como Jean Paul Sallenave, Michael Porter, Kaplan y Norton quienes abren la visión de la responsabilidad social de los directivos hacia los empleados, cuando enfatizan que la empresa es una realidad humana y social formada por personas y recursos económicos, materiales y financieros la cual debe prestar atención a ese talento humano para su crecimiento.

Las personas trabajan para satisfacer necesidades personales. Si una persona entrega su esfuerzo a una empresa, lo hace para conseguir un beneficio económico que le permita adquirir bienes y servicios, desarrollarse individualmente, formarse, facilitar el bienestar y crecimiento de su familia, superar los retos que conlleva el cargo que 
desempeña, trabajar en un ambiente agradable que facilite su labor, como expresa Nuria Chinchilla, investigadora del IESE (2002).

Las personas no se motivan a trabajar solo por factores extrínsecos como el sueldo. Hay otros factores intrínsecos que llegan en la mayoría de los casos a pesar más que los primeros y están relacionados con el salario emocional, la ayuda para su familia, la atractividad del trabajo y la organización.

Desde este punto de vista, la empresa tiene que buscar más allá de que el empleado se identifique con sus objetivos, lo adecuado es que los haga compatibles para que ambos, empresa y empleado, crezcan y se desarrollen. Para ello la estrategia empresarial que busca cuidar el talento humano no tiene que orientarse a hacer el seguimiento tipo policial de qué hace y como lo hace el empleado; es contemplar el plano de para qué se hacen las cosas, es crear valores concretos que ayuden a los directivos a trabajar mejor con sus empleados como colaboradores, donde lo que importa es lo que se hace. Esto conlleva a detectar en los empleados sus debilidades y fortalezas, convertir sus debilidades en fortalezas y entregar mejores empleados a las diferentes áreas de la organización.

Kaplan y Norton (2004) acertadamente se refieren en la perspectiva del crecimiento organizacional y el aprendizaje, base del programa para construir las estrategias y el cuadro de mando integral, a la integración de las personas. Esta perspectiva contiene los componentes de los activos intangibles en donde se encuentra el capital humano, el capital organizacional y el capital de información, elementos que deben estar alineados con los objetivos de los procesos internos integrados y con la estrategia para crear valor. En esta forma, el capital humano requiere del desarrollo de sus habilidades, el talento y el conocimiento para llevar a cabo las acciones que exige la estrategia, condiciones que inducen a la 
empresa a estudiar cada empleado, ver sus fortalezas y debilidades, y capacitarlo con el fin de crear ese valor para los clientes que permita el retorno para los accionistas a través de inversión en las personas.

Así las cosas, la gerencia general y dirección de talento humano deberán ajustar su trabajo incluyendo dos elementos muy importantes en su gestión. El primero, implica considerar que en la empresa se trabaja con personas y estas son influenciadas por su cultura con aspectos visibles y ocultos, que las metas se alcanzan a largo plazo y por lo tanto se aprende de los errores y de los aciertos, que se interactúa en un entorno multicultural y que el talento humano requiere de la contribución de la empresa para su formación profesional y capacitación. Lo segundo, la gerencia de talento humano tiene que orientar su gestión al apoyo de las áreas funcionales identificando debilidades de los empleados para orientar su capacitación, alineada con las estrategias de la empresa para crear valor. Esto significa que debe implementar programas de formación y planes de desarrollo para empleados en función de los intereses de los inversionistas, los clientes, los directivos y de los mismos empleados con beneficios económicos complementarios donde se ofrezca un salario emocional que beneficie a la familia y al trabajador (Ulrich, 1999). Cuando el empleado ve que la empresa contribuye a la generación de valor para él y su familia, la productividad aumenta. La inversión de la empresa en el empleado se refleja en mejores procesos y mayores ingresos a largo plazo que benefician al inversionista al obtener mayores retornos de su inversión.

\section{Tercer componente: los proveedores}

En el entorno global empresarial que se vive hoy, la gestión de proveedores se ha convertido en una de las principales "herramientas competitivas" de 
empresas que quieren mantenerse en el mercado competitivo. El proceso de la gestión de compras y abastecimiento empieza a verse en el mundo empresarial como una oportunidad de agregar valor a la cadena de suministro, así como a los objetivos de negocio. De hecho, es considerada como un área estratégica que impacta positivamente la reducción de costos, el servicio al cliente y los resultados económicos. La rentabilidad, la eficiencia operacional, la alta rotación de los inventarios y la rápida entrega del producto al cliente tienen un enfoque sistémico en la logística integral de las organizaciones, que conforma el Supply Chain Management (SCM).

Sin embargo, esta gestión con los proveedores se está mirando solo desde el punto de vista del negocio en sí. Se orienta a lograr los mejores resultados de servicio y rendimiento económico que favorezcan la empresa desde una sola de las partes, a sacarle el mejor provecho a los acuerdos que haga con los proveedores, de modo que se olvide que ellos también deben buscar resultados similares a los de la empresa que adquiere sus productos $\mathrm{y}$ tiene que responder a su cadena de abastecimiento. El gerente financiero o el gerente de compras se "enorgullecen", y en la mayoría de los casos muestran una sonrisa de satisfacción, porque han logrado una ventaja financiera frente a su proveedor al terminar un acuerdo o negociación, donde prima la posición de "yo gano y usted pierde porque soy más hábil para hacer negocios".

La creación de valor para quienes surten de la materia prima a la empresa, que después de transformarla va al consumidor, debe recibir un trato acorde con el vínculo que representan. El empresario debe pagar el justo precio en el momento que el proveedor espera, y no aprovecharse de él para aumentar su rentabilidad aplazando la cancelación de las facturas. Sucede que, en muchas empresas, no se le cancela al proveedor en la fecha establecida para tomar el descuento por pronto pago. Es una práctica muy 
usual de los tesoreros o gerentes financieros tomar el descuento ofrecido por el proveedor y dejar pasar unos días adicionales para realizar los pagos por la tesorería después del cierre bancario o efectuar una transacción bancaria que generalmente hacen el primer día hábil siguiente al fin de semana. La empresa tiene que generar valor a los proveedores cancelando a tiempo las facturas ya que ellos pertenecen a la cadena de valor y también tienen compromisos financieros con sus proveedores y empleados, como se ha comentado en párrafos anteriores.

Hay que pensar que el proveedor se puede cansar por la ventaja que el comprador asume; bien podría suspender la entrega oportuna de materia prima o no volver a vender, y de esta manera perjudicar al productor. La no entrega oportuna de la materia prima de buena calidad afecta a la empresa en la entrega del producto a sus clientes. Se insiste que este proveedor también tiene una cadena de abastecimiento que lo compromete con sus proveedores en la creación de valor y, en muchos de los casos, tiene que recurrir al crédito bancario para cumplir sus compromisos.

Esta gestión de creación de valor al proveedor se relaciona con el proceso de negociación. Es muy importante para el directivo que gestiona las relaciones con los proveedores mire como se ejecuta la posición gana-gana. Siguiendo a Margarita Canal (2007), lo relevante es mantener una cultura de negociación colaborativa en las empresas de modo que se evite desviar este concepto a una situación de división igualitaria de recursos o construir una relación entre las partes y menos "yo gano y usted pierde, si quiere mantener las relaciones comerciales conmigo". Es esencial saber que se pueden usar estrategias para reclamar y para crear valor. Es necesario reconocer que quien negocia intenta conseguir la mayor cantidad posible de elementos que representan valor para la empresa, como el tiempo, el dinero, los derechos. 
Asimismo, se debe aplicar como principio que quien negocia obtiene el mejor provecho posible, entender que en la negociación se genera algo nuevo que no se había contemplado al principio del diálogo, de manera que se logre no solo la meta trazada sino buscar en el proceso mejorarla y garantizar simultáneamente que la contraparte satisfaga sus propósitos de manera óptima. Es necesario buscar en los acuerdos agrandar la torta profundizando en los intereses de cada parte y satisfaciendo sus necesidades con acuerdos integrativos y colaborativos.

Cuando el proveedor ve que el comprador honra su palabra cumpliendo los acuerdos y le genera valor, el resultado es que la entrega de la materia prima o el servicio se hace a tiempo, de la mejor calidad, contribuye a la creación de valor para el consumidor de quien es su cliente o comprador y colabora en el Lean de la cadena de abastecimiento que al final beneficia al cliente.

\section{El cuarto componente: stakeholders}

Este componente lo conforman las entidades del sistema financiero. Estas son las instituciones con las cuales la empresa tiene vinculación por la prestación de servicios financieros. De ellas, principalmente se obtienen los préstamos y cupos de crédito para mantener el equilibrio financiero y la liquidez para cumplir con los compromisos operacionales; unos vinculados al capital de trabajo para atender las actividades cotidianas y otros dirigidos a la inversión en activos fijos que contribuyen a las actividades de producción y al crecimiento empresarial.

Es común en algunas empresas que se trate de engañar a la entidad financiera con cifras no reales con el propósito de alcanzar los préstamos, entregar garantías insuficientes, en algunos casos ajustadas a los valores de respaldo, y cancelar en mora o intencionalmente dejar la cartera 
vencida para que sea castigada por la entidad financiera al cabo de un año. También lo es hacer proyecciones financieras en las empresas con cifras no reales y especulativas, soportadas en supuestos, para demostrar eficiencia y generación de ingresos que al final no se cumplían. Una práctica similar y muy usual se dio, en los años setenta y ochenta: los gerentes de empresa buscaron engañar a las entidades del sistema financiero, mientras los clientes "compraban" a los representantes bancarios para obtener préstamos y sus garantías estaban "infladas", lo que llevaba a la pérdida de capitales en las instituciones financieras, a pesar de recibir daciones en pago.

Es importante dejar la actitud antiética de dar participación a los directivos relacionados con el crédito de sus beneficios económicos futuros, entregando "por debajo de la mesa" coimas para agilizar o asegurar las solicitudes de préstamos o, en la mayoría de los casos, hacer invitaciones costosas a cenar para manipular e influenciar las operaciones. Esas disculpas y justificaciones de hacer el "lobby" deben acabarse. Hay que obrar con total transparencia en estos casos.

Pero, como en estas actividades donde juega la responsabilidad social debe existir la contraprestación, las entidades financieras deben responder con similar servicio social, otorgando préstamos sin reciprocidad en depósitos, aplicando tasas activas razonables y evitando el anatocismo, operación financiera que hoy se disfraza cubriéndose del incumplimiento legal con la refinanciación de la deuda y el costo en mora.

La empresa tiene la obligación de pagar a tiempo sus deudas para mantener una imagen limpia en el sector bancario y financiero, que le permita en cualquier momento acceder a financiaciones de sus proyectos, con lo cual proyecta su imagen ética a la sociedad con sus actuaciones basadas en principios y valores sociales 


\section{Quinto componente: el Gobierno}

Es una práctica muy común el buscar evadir desde muchas acciones el pago de impuestos; en ocasiones, se utilizan formas para reducir las utilidades con gastos no reales, cambios permanentes en los sistemas de amortización, etc. En otras, se proyectan donaciones a fundaciones sin ánimo de lucro, ya sean de propiedad de la empresa o del grupo empresarial o de otro sector externo, con lo que se busca obtener certificaciones que les faciliten deducciones tributarias no muy transparentes. En primer término, la empresa debe pagar los impuestos que le corresponden, así el Gobierno los utilice inadecuadamente; en segundo lugar, si lo que quiere hacer es una obra social no se debe esperar una retribución. Tiene mucho mayor valor hacer la donación silenciosamente, lo cual refleja sentido espiritual, si es que ese es el verdadero propósito o intensión humanitaria de la empresa o del inversionista.

El sector fiscal, entendido como el Estado moderno, ejerce una importante influencia sobre la economía de un país, como consecuencia de las insuficiencias o ineficiencias de los mercados, dice Cesar Ferrari (2008). El cumplimiento de estas responsabilidades o desarrollo de unos bienes públicos, y otros no públicos como la infraestructura, requiere de unos recursos; es decir, para cubrir esos gastos que demandan las actividades contributivas al desarrollo, es necesario el ingreso que proviene principalmente de los impuestos. Para ofertar esos bienes, el Estado, como una empresa común y corriente, compra bienes y servicios, paga salarios, paga deudas, toma créditos, crea dinero y efectúa transferencias. De aquí se desprende que el Estado juega un papel importantísimo en la economía y es el principal promotor del crecimiento económico y generador de empleo. 
En consecuencia, si las empresas no cancelan el impuesto que les corresponde, buscan formas de evadir el pago de sus impuestos, el Estado no puede contribuir a la generación de riqueza, expandir la economía, estabilizarla y distribuir el ingreso equitativamente. En otras palabras, el no pago de impuestos correctamente no crea valor para el Estado y para el pueblo que conforma un país.

\section{El sexto componente: la conservación del medio ambiente}

Cuidando el planeta en el que vivimos, aportamos para mejorar la calidad de vida de quienes lo habitamos. Las campañas que hoy se promueven a nivel mundial no obedecen a una inquietud nueva; el planeta siempre ha estado en peligro por los efectos de la contaminación, la deforestación, la falta de cuidado de zonas que menos recursos tienen y donde habitan personas que se impactan negativamente y requieren de recursos naturales para sobrevivir.

Las empresas deben tomar consciencia sobre el ecosistema; es imperativa la necesidad de proteger el medio ambiente y los recursos naturales, cumplir las leyes que se orientan a proteger bienes como el agua, la tierra, el aire, el suelo, la flora, la fauna; todo lo que se puede llamar los bienes ambientales. No es justificable que el hombre destruya el medio ambiente para satisfacer sus necesidades individuales, para satisfacer las necesidades empresariales económicas que buscan, a través del desarrollo de proyectos de inversión, incrementar su beneficio económico.

Esta posición es contradictoria y riñe con la maximización del patrimonio del inversionista que pretende generar nueva riqueza con responsabilidad social, concepto económico que se enmarca en la distribución equitativa de recursos escasos. 
En este sentido, se ha encontrado un modelo económico que propicia la destrucción lenta del planeta, que no tiene en cuenta el correcto aprovechamiento de los recursos naturales y ambientales del planeta, por cuanto los intereses de los directivos y de los accionistas es maximizar el poder económico que le genera el incremento de las utilidades que busca a como dé lugar. Los equilibrios ecosistémicos pueden llevar a que el hombre elimine poco a poco sus condiciones de subsistencia. En otras palabras, el hombre necesita de la naturaleza y de los equilibrios ambientales que garanticen su existencia y contribuyan a la satisfacción de sus necesidades personales como ser humano.

Las empresas deberían tener una contabilidad ambiental obligatoria donde muestren los recursos económicos que orientan a la protección del medio ambiente. Autores reconocidos en el campo de la economía ecológica y política ambiental como Enrique Leff, Joan Martinez Alier (economista y catedrático de Economía e Historia Económica en la Universidad Autónoma de Barcelona), Arturo Escobar (antropólogo y profesor en la Universidad de Carolina del Norte en Chapell Hill) y Danilo Ariza $^{1}$, entre otros, plantean posiciones muy claras con respecto a la implementación y buena gestión ambiental que puede ayudar a la contabilidad orientada al reconocimiento del gasto por la protección del medio ambiente. Sin embargo, en la práctica, al parecer la gestión se dirige a incrementar las utilidades operacionales de las empresas y en consecuencia el valor de las acciones en el mercado.

Por ejemplo, la moda es una política "cero papel”, donde abiertamente le trasladan al usuario la impresión de las certificaciones o documentos, que por derecho debe generar la empresa y, por ende, el gasto de la impresión.

\footnotetext{
${ }^{1}$ Autor de varios artículos sobre contabilidad ambiental y responsabilidad social, entre ellos El camino hacia la revelación: evolución de los informes sobre responsabilidad social en Colombia (2006-2009), Facultad de Ciencias Económicas, Universidad Militar.
} 
Esos ahorros llevan simplemente a incrementar las utilidades de operación de la empresa a costa del usuario o consumidor, con lo que le resta valor a este último. Otras empresas, con autorización del Estado y escudadas en su objeto social, orientan sus inversiones a la explotación de bosques y selvas naturales dañando el ecosistema para obtener beneficios económicos. Esto no es ético ni obedece a una política de protección ambiental. En la Unión Europea² ${ }^{2}$ he ha reconocido que las industrias de plásticos y de consumo masivo rápido adquieren compromisos que no son suficientes para contener la contaminación y se encuentran desarrollando nuevas leyes que responsabilicen a las compañías por los residuos que generan.

Desde la contabilidad, se puede contribuir a una mejor administración ambiental modificando los sistemas contables, la planeación de los proyectos financieros relacionados con el medio ambiente, la presentación del desempeño ambiental de la gerencia y la generación de informes periódicos como los denominados ecobalances para que la sociedad se informe de la gestión y compromiso social responsable.

El empresario debería destinar en sus presupuestos una suma de dinero representativa, que provenga de sus utilidades operacionales, sin trasladárselas al consumidor al incrementar los precios de los bienes y servicios que le entrega, para llevarlas al cuidado ambiental, la construcción de hospitales, vías de acceso fáciles en ciertas regiones necesitadas, limpieza de los ríos, construcción de equipos para evitar la contaminación, mejores tierras para producir alimentos y otras actividades similares. Lo importante es implementar estrategias integrales para la

\footnotetext{
${ }^{2}$ Según informe publicado por Greenpeace International, en octubre 23 de 2018, once corporaciones como Coca Cola Company, Colgate Palmolive, Danone, Johnson y Johnson, Kraft Heinz, Mars, Nestlé, Mondelez, PepsiCo, Procter \& Gamble y Unilever son responsable de la alta contaminación mundial.
} 
protección del medio ambiente, no limitarse solo a registrar algunos gastos orientados a su protección. Deben adquirir un mayor compromiso social.

Cuando la sociedad perciba que esa empresa destina recursos para proteger la naturaleza y el medio ambiente de su región, en beneficio de su salud y satisfacción de otras necesidades que contribuyan a su subsistencia, apoya a esa organización adquiriendo sus productos, bienes o servicios en contraprestación social y económica. Miremos las acciones de uno de los hombres más ricos del mundo y su orientación a la conservación del medio ambiente en beneficio de la sociedad:

La Revista Semana publicó el 7 de diciembre de 2019 un comunicado de BBC Mundo sobre Bill Gates:

El cofundador de Microsoft no solo es conocido por ser uno de los hombres más ricos del mundo, sino también por financiar proyectos filantrópicos e ideas "locas" para salvar al mundo, como él mismo dice en broma.

Ha donado recursos para la lucha contra el VIH-sida, diseños de retretes que reciclan agua para comunidades sin servicios públicos, campañas de vacunación contra la polio que decidían qué territorios cubrir a través de algoritmos, entre otras causas.

Quizás ninguna ha sido tan ambiciosa como en la que ha trabajado en la última década: poner en marcha una fuente de energía que sea segura y limpia. (“Así era el ambicioso...”, 2019)

Cuando el propósito es destinar recursos económicos y monetarios de la empresa para la protección del medio ambiente, se contribuye a la maximización de la rentabilidad del patrimonio o creación de nueva riqueza para el inversionista, porque el consumidor responde. 


\section{Séptimo componente: los accionistas de la empresa}

Si la maximización del valor o creación de nueva riqueza para el accionista, en condiciones de certeza, es el propósito financiero, la empresa en cabeza del director de esta área debe buscar que las demás dependencias como la dirección comercial, la de mercadeo, la administrativa, la de talento humano y la de producción contribuyan con la creación de valor para sus grupos de interés.

El director financiero, desde su campo de acción, debe buscar que los proyectos de inversión contribuyan a la creación de riqueza con el fin de lograr la maximización de la rentabilidad, de tal manera que el valor presente de los insumos utilizados en el proyecto sean mayores al valor presente de los insumos requeridos para llevar a cabo la inversión. Así lo afirma Solomon (1972), cuando habla de obtener un beneficio adicional, que es la creación de valor para el accionista. Este criterio es aplicable al sector público, donde los mismos problemas de asignación y costo de capital se deben evaluar en las decisiones de inversión.

Si las diferentes dependencias están enfocadas a la creación de valor para sus grupos de interés, se van a concentrar recursos de la empresa en generar permanentemente ingresos que maximicen su patrimonio con responsabilidad social. Al cumplir este objetivo, habrá correspondencia y reciprocidad positiva de los componentes del grupo de stakeholders, lo que le devuelve valor a largo plazo para la empresa a través de la fidelización.

Cuando la empresa genera valor para el consumidor con un producto de buena calidad, cuando genera valor para sus empleados contribuyendo a su crecimiento personal y familiar, cuando genera valor para el proveedor al hacer negociaciones justas y colaborativas "gana-gana", cuando genera valor a las entidades del sector financiero cancelando sus obligaciones a 
tiempo y sin engaños, cuando genera valor al gobierno pagando los impuestos que corresponden, sin evasiones ni artimañas, cuando genera valor al medio ambiente contribuyendo a su conservación con una participación real y efectiva, se genera valor para el accionista. Los ingresos futuros generados por sus operaciones, traídos al presente, son mayores a los recursos invertidos (figura 3).

Figura 3. Representación gráfica del flujo de beneficios futuros comparados con la inversión inicial

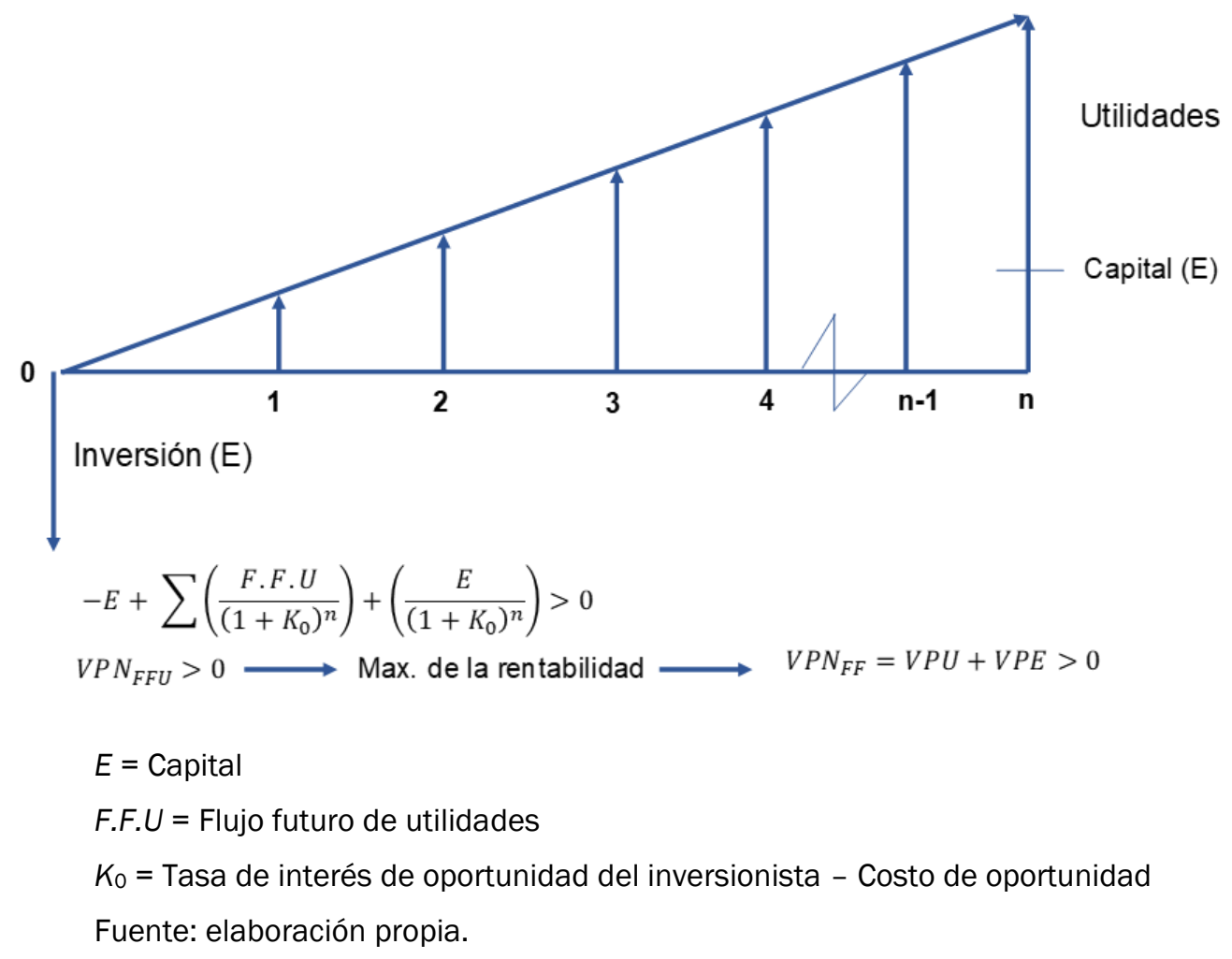

Al generarse un valor actual neto positivo, se cumple el objetivo operativo de la gerencia financiera, que es generar valor para el accionista. El efecto en el mercado de capitales es claro, el valor de la acción se incrementa, se pueden pagar a futuro mejores dividendos y la sociedad ve a la empresa como un ente económico transparente que contribuye a la solución de sus necesidades. 
Este concepto de maximización del beneficio o creación de valor para la empresa y sus dueños permea todo tipo de organizaciones, aquellas que buscan beneficios económicos y financieros, sin ánimo de lucro, y entidades del sector público. En todas ellas se debe incluir, en la toma de decisiones de inversión, la responsabilidad social o generación de valor para sus grupos de interés con el fin de alcanzar propósitos de mutuo beneficio que permanezcan a largo plazo y se involucre el riesgo.

\section{Conclusiones}

La responsabilidad social empresarial (RSE) forma parte del deber ser de la empresa, por lo que debe entenderse como una labor colaborativa de la empresa para el desarrollo de la sociedad, que no es la satisfacción de la pobreza. Es un proceso de expansión de las capacidades de la gente para elegir el modo de vida que ella valora. Es una actitud responsable del empresario ante el sentido del trabajo que lo enriquece a sí mismo, que enriquece el trabajo y que enriquece a la sociedad.

Conocer las maneras de aplicar dicha acción, así como los motivos y los sistemas de evaluación para juzgar la acción, permite fundamentar las conductas de las empresas y sus dirigentes. Lo visto hoy en la forma de actuar de las empresas hace necesario repensar los roles de los directivos, la sociedad y empresarios para plantear un desarrollo basado en el valor para las partes. Esa ideología, fundamentada en el sistema clásico capitalista, donde el inversionista está interesado en su propio beneficio, debe reemplazarse por la toma de decisiones desde el interior de la empresa, que represente no solo el interés de los propietarios, sino el de todos los sectores relacionados con la empresa, incluyendo a los consumidores, los empleados, los proveedores, los acreedores, el Gobierno, el medio ambiente - que tanta relevancia ha tomado desde finales del siglo pasado- y al mismo inversionista, quien ve incrementada 
su rentabilidad cuando se satisfacen los intereses de quienes lo apoyan en el crecimiento de su empresa o negocio.

La responsabilidad social del empresario frente a la sociedad no es entonces incluir una palabra de moda en la redacción de la misión y la visión y obtener el certificado de calidad, ni es un eslogan y, menos, una frase que se incluye en los planes estratégicos para cumplir los requisitos de una estructura organizacional. Es definir en la práctica la identidad de la empresa como una obligación para satisfacer las necesidades mínimas de los stakeholders, la creación de valor al satisfacer sus necesidades. Podría definirse el objetivo operativo de la gerencia financiera como la maximización del patrimonio o creación de nueva riqueza para el accionista, en condiciones de certeza. Permite que el director financiero gestione una responsabilidad social que genere valor al consumidor, los empleados, los proveedores, las entidades financieras, el gobierno y el medio ambiente. Como la empresa interactúa en la sociedad, la responsabilidad social debe darse en doble vía, la empresa entrega valor y recíprocamente los stakeholders mantienen su vínculo con la empresa devolviendo ese valor con una relación permanente, colaborativa y transparente; con esto, se apoya el proceso al satisfacer las necesidades de la empresa, lo cual se traduce en un mayor valor económico y valorización de sus acciones en el mercado.

Es claro que, en la maximización de la rentabilidad para el inversionista, hay en juego papeles importantes como la ética, los valores empresariales, el riesgo y la generación de valor para la sociedad y sus grupos de interés.

\section{Referencias}

Bodie, Z. y Merton, R. (1999). Finanzas (1. ${ }^{\mathrm{a}}$ ed.). Prentice Hall. 
Block S. B. y Hirt G. A. (2001). Fundamentos de gerencia financiera (9. $\left.{ }^{\mathrm{a}} \mathrm{ed}\right) . \mathrm{McGraw}$ Hill.

Brealey, R., Myers, S. y Allen, F. (2007). Principios de finanzas corporativas (9. ${ }^{\mathrm{a}} \mathrm{ed}$. .). McGraw Hill.

Brigham, E. y Ehrhardt, M. (2007). Finanzas corporativas (2. ${ }^{\mathrm{a}}$ ed.). Cengage Learning.

Cajiga, J. F. (2011). El concepto de responsabilidad social empresarial. Centro Mexicano para la Filantropía.

Canal, A., M. (2007). Del dicho al hecho hay mucho trecho: ¿Cómo pasar del discurso "gana-gana" a una actitud auténtica de colaboración en las negociaciones? En F. Azuero Zúñiga, A. C. González León y M. L. Gutiérrez Botero (eds.), Tendencias de la administración (Vol. II, pp. 379-395). Ediciones Uniandes.

Concilio Vaticano II (1963). Gaudium et Spes. https://www.vatican.va/archive/hist councils/ii vatican council/documents/vatii const 19651207 gaudium-et-spes sp.html

Davis, K., Frederick, W. y Blomstrom R. (1980). Business and Society: concepts and policy issues (4. ${ }^{\mathrm{a}}$ ed). McGraw Hill.

De Lara Haro, A. (2004). Medición y control de riesgos financieros ( $3 \cdot^{\mathrm{a}}$ ed.). Editorial Limusa; Grupo Noriega Editores.

Drucker, P. (2001). Management challenges for the 21st Century. Transaction Publishers. (Original publicado en 1984).

Ferrari, C.A. (2008). Política económica y mercados ( $3 \cdot^{\mathrm{a}}$ ed.). Pontificia Universidad Javeriana.

Flores, J., Ogliastri, E., Peinado-Vara, E. y Petri, I. (2007). El argumento empresarial de la RSE: 9 casos de América Latina y el Caribe. Banco Interamericano de Desarrollo. INCAE Business School. https://publications.iadb.org/publications/spanish/document/El-argumentoempresarial-de-la-RSE-9-casos-de-Am\%C3\%Agrica-Latina-y-el-Caribe.pdf

Friedman, M. (1970, 13 de septiembre). The Social Responsibility of Business is to Increase its Profits. The New York Times.

https://www.nytimes.com/1970/09/13/archives/a-friedman-doctrine-the-socialresponsibility-of-business-is-to.html

Revista Activos

ISSN: 0124-5805 | e-ISSN: 2500-5278 | DOI: https://doi.org/10.15332/25005278

Vol. 19 N. ${ }^{\circ} 1$ | enero-junio de 2021 
Instituto Colombiano de Normas Técnicas y Certificación. (2006). Instituto Colombiano de Normas Técnicas y Certificación. Estado del arte con respecto al movimiento de difusión, normalización y certificación de la responsabilidad social a nivel mundial.

Juan Pablo II. (1991). Encíclica Centesimus Annus.

Jensen, M. (2002). Value maximization, stakeholder theory and the corporate objective function. Business Ethics Quarterly, 12(2), 235-256. https://doi.org/10.2307/3857812

Kaplan, R. y Norton D. (2004). Mapas estratégicos: convirtiendo los activos intangibles en resultados tangibles. Gestión 2000.

Norton, D. y Kaplan, R. (2011, 12 de mayo). Gestión estratégica, liderazgo y gestión de riesgos. Seminario, Cámara de Comercio de Bogotá, Cafam y Strategy and Results, Bogotá, Colombia.

Melé, D. (2004). La relación empresa sociedad como base para la responsabilidad de la empresa en la sociedad. En M. Paladino (ed.), La responsabilidad de la empresa en la sociedad construyendo la sociedad desde la tarea directiva. (cap. 5, pp. 153160). Arial Sociedad Económica.

Paladino, M. (2004). La responsabilidad de la empresa en la sociedad: construyendo la sociedad desde la tarea directiva. Ariel Sociedad Económica.

Paladino, M. y Milberg, A. (2004). Conceptos y tendencias. En M. Paladino (ed.), La responsabilidad de la empresa en la sociedad construyendo la sociedad desde la tarea directiva (cap. 1). Arial Sociedad Económica.

Preston, L. E. y Post, J. E. (1975). Private management and public police: the principle of public responsability. Prentice Hall.

Así era el ambicioso de Bill Gates para salvar el planeta. (2019, 7 de diciembre). Semana Sostenible. https://www.semana.com/medio-ambiente/articulo/asi-era-elproyecto-de-bill-gates-para-salvar-el-planeta-quedo-frustrado-por-la-guerracomercial-de-trump-con-china/47905/

Ross, S., Westerfield, R. y Jordan, B. D. (2006). Fundamentos de finanzas corporativas ( $7 .^{\mathrm{a}}$ ed.). McGraw Hill Interamericana. 
Sanborns, C., Portocarrero, F. (2003). La Filantropía en América Latina: los desafios de las fundaciones donantes en la construcción del capital humano y justicia social. Centro de Investigaciones de la Universidad del Pacífico (CIUP). http://www.prohumana.cl/minisitios/seminario/download/sanborn portocarrero .pdf

Solomon, E. (1972). Teoría de la administración financiera (D. J. Messuti, trad.). Ediciones Machi.

Salekman, B. Citado por Melé, p.159.

Saldivar, A. (1999). Planeación financiera de la empresa $\left(3 \cdot{ }^{\mathrm{a}}\right.$ ed.) Trillas.

Tinoco-Cantillo, U. A., Arango-Buelvas L. J. y Benavides, O. (2012). Evolución, aproximación al concepto y teorías de responsabilidad social empresarial.

Panorama Económico, 20: 189-220. https://doi.org/10.32997/2463-0470-vol.20num.0-2012-344

Ulrich, D. (1999). Recursos humanos Champions. Granica.

Van Horne, J. y Wachowicz J. M. (2002). Fundamentos de administración financiera (9. ${ }^{\mathrm{a}}$ ed.). Pearson Prentice Hall.

Votaw, D. (1972). Genius became rare: a comment on the doctrine of social responsibility. California Management Review, 15(2), 25-31.

Chan Kim, W. y Mauborgne, R. (2005). Blue Ocean Strategy. Harvard Business School Publishing Corporation. 